\title{
Secondary metabolites of the leaf surface affected by sulphur fertilisation and perceived by the diamondback moth
}

\section{Cristina Marazzi, Bruno Patrian and Erich Städler}

Eidg. Forschungsanstalt, Postfach 185, CH-8820 Wädenswil, Switzerland

Summary. Oilseed rape, Brassica napus L. (cv Express), plants were grown under three different sulphur regimes: sulphur-free $\left(\mathrm{S}_{0}\right)$, normal sulphur $\left(\mathrm{S}_{\mathrm{n}}\right.$, normal field concentration) and a sulphur-rich $\left(\mathrm{S}_{+}, 2 \times\right.$ concentration of $\left.\mathrm{S}_{\mathrm{n}}\right)$. We performed dual choice oviposition assays with the diamondback moth, Plutella xylostella, using real plants and, for the first time with this insect, artificial leaves sprayed with methanolic leaf-surface extracts. The results mirrored those of a separate study of preferences for whole plants. Females laid more eggs on surrogate leaves that were treated with $S_{n}$ extracts than on $S_{0}$ plants, while only a slight, not significant, difference was observed between extracts of normal and sulphur-rich plants. This shows that chemical compounds on the leaf surface mediate the oviposition preference and that the female insect can perceive the quality of the host-plants in terms of their fertilisation status.

Since leaf volatiles are known to be oviposition stimulants, we investigated the effects of leaf-surface extracts on insect olfactory responses using electroantennograms (EAGs). In agreement with the behavioural data, we found that extracts of sulphur-treated plants yielded higher EAG amplitudes than the $S_{0}$ extracts. Since the leaf content of the volatiles isothiocyanates is influenced by sulphur nutrition, we analysed the extracts for these compounds. Above the detection threshold of our GC-MS system, no isothiocyanates were found. Thus, other compounds present in the surface extracts must be perceived by the antenna.

However, the HPLC analysis revealed 11 different glucosinolates. Progoitrin (2-Hydroxy-3-butenyl) and gluconapoleiferin (2-Hydroxy-4-pentenyl), which belong to the hydroxy-alkene class of glucosinolates, were the most abundant compounds. The total glucosinolate content sharply increased from $S_{0}$ to $S_{n}$ plants, whereas it was slightly lower in $S_{n}$ versus $S_{+}$plants. Since it is known that glucosinolates can stimulate oviposition, it seems likely that the increased content we observed was influencing the insect preference in this study too.

Key words. Oilseed rape - Brassica napus - glucosinolates isothiocyanates - Plutella xylostella - oviposition choice EAG, HPLC, GC-MS

\section{Introduction}

The diamondback moth, Plutella xylostella (L.), is a harmful pest of cruciferous crops throughout the world (Harcourt 1957). In our previous investigation of the effects of sulphur (S) plant nutrition on oviposition of the diamondback moth (Marazzi \& Städler, in preparation) we found that moths clearly discriminate between $\mathrm{S}$ fertilised and non-fertilised Brassica napus oilseed plants. The question arising was which plant characteristics the moth females perceive.

In Brassicaceous plants, $\mathrm{S}$ is used in the synthesis of secondary metabolites like glucosinolates (GSLs) (Chew 1988), phytoalexins (Pedras et al. 2000) and CIF ("cabbage identification factor"; 1,2-dehydro-3-thia-4,10,10b-triazacyclopenta[.a.]fluorine-1-carboxylic acid) (Hurter et al. 1999). Volatile chemicals mainly produced by hydrolysis of non-volatile GSLs (Pivnick et al. 1994) are also known to be involved in host-plant location by different insects attacking this plant family (Blight et al. 1995). Gupta and Thorsteinson (1960a, b) have demonstrated that constituents of host-plants affected larval feeding and oviposition of P. xylostella. Later studies confirmed that host recognition and oviposition by this insect is dependent on GSLs. Reed et al. (1989) used plant extraction followed by myrosinase treatment to show that the stimulant activity was greatly reduced after hydrolysis of the GSLs. Individual GSLs were also active but not to the same extent as homogenised plant tissue.

The presence of GSLs in crucifers is strictly dependent on the medium in which the plant is grown (Schnug 1997). In this context, Meyer (2000) showed that soil fertility affects both the degree of defoliation and compensation for herbivory in Brassica nigra plants damaged by Pieris rapae caterpillars. Oligophagous insects such as diamondback moth larvae accept as food the leaves of only a limited number of plant species. The actual selection of the hostplant is performed by the ovipositing female (reviewed in Marazzi \& Städler, in preparation), as the mobility and energy reserves of the first instars are limited and the opportunities to find a suitable host on their own are minimal (Justus \& Mitchell 1996).

In the present work, $\mathrm{S}$ was used as a variable environmental factor, since this mineral is clearly involved in the production of secondary plant metabolites that have key roles as attractants, feeding (Renwick 2002) and oviposition stimulants (Justus \& Mitchell 1996; Hughes et al. 1997; Spencer et al. 1999) for Plutella xylostella. Gupta and 
Thorsteinson (1960a) first studied the effect of $S$ mineral nutrition in two Brassica species (B. alba and B. nigra). They found that $P$. xylostella laid more eggs on the $\mathrm{S}$ fertilised plants than the $\mathrm{S}$ deficient controls. Although these differences were not significant, they seemed to be suggestive. This prompted us to study the indirect influence of $S$ fertilisation on the behavioural and physiological responses of female diamondback moths to Brassica napus (L.) plant extracts hoping to find the plant characteristics related to the observed preference.

\section{Materials and methods}

\section{Insects}

All the Plutella xylostella (L) (Lepidoptera: Plutellidae) required for the bioassays came from our laboratory culture established with approximately 200 individuals during spring 2000 and reared as described by Marazzi \& Städler (in preparation). Briefly, an equal number of male and female mature moths (approximately 100 per cage) were held in mesh cages $(50 \times 45 \times 45 \mathrm{~cm})$ in a climatecontrolled room $\left(21 \pm 1^{\circ} \mathrm{C}, 70 \% \mathrm{RH}\right.$ and $16 \mathrm{~h}$ photophase), where they were allowed to mate and oviposite only on the leaves of potted $(\varnothing 13 \mathrm{~cm})$ B. napus cv CC-Cross F1 at the pre-bolt stage. The moths had access to a source of water and to $10 \%$ sugar-water.

\section{Plants}

The oilseed rape (B. napus cv. Express) was grown as described by Marazzi \& Städler (in preparation). Briefly, a modified "Hoagland" nutrient solution was used to provide the three different $\mathrm{S}$ levels of fertilisation: $\mathrm{S}_{\mathrm{n}}=1 \mathrm{mM}$ of $\mathrm{MgSO}_{4}$ (normal S concentration in a Swiss field); $\mathrm{S}_{+}=2 \mathrm{mM}$ of $\mathrm{MgSO}_{4}$ (high sulphur level) and $\mathrm{S}_{0}$ (S-free level), which was obtained by replacing $\mathrm{MgSO}_{4}$ with $\mathrm{MgCl}_{2}$ $(1 \mathrm{mM})$. All the experiments were conducted using plants with 3-4 true leaves (30-35 days after planting), comparable in size.

\section{Oviposition choice assay}

Bioassay with real plants: We attempted to relate our oviposition data on real plants with the glucosinolate content of the three samples of B. napus plants $\left(\mathrm{S}_{0}, \mathrm{~S}_{\mathrm{n}}\right.$ and $\left.\mathrm{S}_{+}\right)$. For this purpose we used the data concerning the oviposition choice assay with real plants from Marazzi and Städler (in preparation), where we tested $4 \mathrm{~B}$. napus plants at a time (2 plants per cage for each treatment, i. e. $S_{n}$ vs $S_{0}$ or $\mathrm{S}_{\mathrm{n}}$ vs $\mathrm{S}_{+}$) for a period of 24 hours, during which about one hundred 1-2 day-old diamondback moths were released into each cage and were allowed to mate and oviposit on plants $(n=20)$.

Bioassay with artificial leaves: We used the same extraction procedure as described by Baur et al. (1996) to obtain wax-free methanolic leaf-surface extracts of $S_{0}, S_{n}$ and $S_{+}$plants at the 3-4 true leaf stage. Amounts and concentrations of samples were expressed in gle (gram leaf equivalent) or gle/ml, respectively. One gle represents the amount of leaf surface extract obtained by dipping $1 \mathrm{~g}$ of fresh leaf material.

The oviposition substrates used in the experiments consisted of paraffin-coated green paper model leaves developed originally for the cabbage root fly by (Roessingh \& Städler 1990) with a surface projection of $7 \times 7 \mathrm{~cm}, 1.5 \mathrm{~cm}$ wide vertical folds and a flat stem of $5 \times 1.5 \mathrm{~cm}$. Leaves were individually inserted into hydroscopic foam (Smithers-Oasis, Germany D-67269) cylinders $(8 \mathrm{~cm}$ in diameter, $5 \mathrm{~cm}$ high) and placed in plastic containers $(9 \mathrm{~cm}$ in diameter, $5 \mathrm{~cm}$ high). The top of each container was covered with a black plastic layer $(9 \mathrm{~cm}$ in diameter). Surrogate leaves were sprayed using an airbrush (Aerograph Sprite, Devilbiss) in a fume hood with 1 gle of the extract to test.

All the oviposition bioassays were conducted in the same cages as those described for the rearing (about 100 adult moths per cage). Four plants (or four surrogate leaves) were arranged in a circle on the floor of the cage ( 2 for each treatment: $S_{n}$ (control) vs $\mathrm{S}_{0}$ or $\mathrm{S}_{\mathrm{n}}$ (control) vs $\mathrm{S}_{+}$). After an oviposition period of 24 hours, the eggs laid on each plant or artificial leaf were counted and expressed as a percentage of the total number of eggs laid on all plants within one replicate. Thus, the resulting preference values for the treatments compared $\left(S_{n}\right.$ vs $S_{0}$ and $S_{n}$ vs $S_{+}$respectively) totalled $100 \%$. A Mann-Whitney U-test was performed to determine the significant differences in preference between treatments. For each pair-wise assay, $9\left(\mathrm{~S}_{0}\right.$ vs $\left.\mathrm{S}_{\mathrm{n}}\right)$ and $13\left(\mathrm{~S}_{\mathrm{n}}\right.$ vs $\left.\mathrm{S}_{+}\right)$repetitions were performed and after each replicate, the plant or artificial leaf positions were changed clockwise.

\section{Chemical analysis of glucosinolates}

The surface extracts of $B$. napus grown under the $\mathrm{S}_{0}, \mathrm{~S}_{\mathrm{n}}$ or $\mathrm{S}_{+}$ regimes and a total leaf extract (homogenate) of each plant group were assayed for their GSL content. For each treatment, 15 plants were removed from the pots and the sand was gently washed from the roots using the same nutrient solution to prevent contamination. Plants were then separated into roots and aerial parts, frozen in liquid nitrogen, crushed into small pieces and stored at $-20^{\circ} \mathrm{C}$ until needed. Prior to analysis, samples of both plant parts were ground to a fine powder at $-18^{\circ} \mathrm{C}$ with a coffee mill, $10 \mathrm{~g}$ weighed out, placed in $50 \mathrm{ml}$ glass flasks and stored at $-20^{\circ} \mathrm{C}$ until needed.

We used the same extraction procedure described by Griffiths et al. (2001) to obtain desulfoglucosinolates. The glucosinolates, twenty $\mu \mathrm{l}$ aliquots (representing approximately 2 leaves), were analysed by HPLC. The analytical column used was equipped with a Lichrospher (100 RP $18,5 \mu \mathrm{m}, 4 \times 250 \mathrm{~mm}$ ). The binary mobile phase system was composed of distilled water (A) and water : acetonitrile, $80: 20$ (B). The analysis was run with the following gradient program: 0 to 45 min linear gradient 0 to $100 \% \mathrm{~B}$ and then held for $5 \mathrm{~min}$ on $100 \% \mathrm{~B}$. The flow rate was $1 \mathrm{ml} / \mathrm{min}$ and the detection of desulfoglucosinolates was monitored with an UV/VIS detector at $230 \mathrm{~nm}$.

Quantifications were based on 2 GSL standard solutions (Doon Major and Dwarf), prepared and quantified at the SCRI in Dundee, Scotland. The Jasco HPLC system was equipped with Chromeleon software, which was used for data acquisition and analyses. Reported quantifications are the means of five separate extractions and analyses. The amounts of GSLs from individual peaks were summed and these values were analysed by ANOVA to determine differences between treatments. The GSLs nomenclature is based on the identification list of Griffiths and al. (2001).

\section{Chemical analysis of isothiocyanates}

Isothiocyanates in the plant extracts were analysed by combined gas chromatography and mass spectrometry using a Finnigan Voyager GC-MS System. The GC was equipped with a fused silica capillary column: DB-5 (30 m, $0.25 \mathrm{~mm}, 0.25 \mu \mathrm{m}$ coating). Each plant eluates were prepared by shaking $2 \mathrm{ml}$ crude extract with $2 \mathrm{ml}$ hexane. Two $\mu \mathrm{l}$ of the hexane fraction of each sample were injected splitless using an auto sampler (PAL, CTC-Analytics). Identifications and quantifications were made by external calibration, comparing obtained mass spectra and retention times with those of 4 pure isothiocyanataes (phenyl-, butenyl-, benzyl- and allyl-isothiocyanates). The detection threshold was $1.5 \mu \mathrm{g} / \mathrm{ml}$ crude extract.

\section{Electrophysiology}

Female diamondback moths, 1-2 days old, were cooled in a refrigerator $\left(5.5^{\circ} \mathrm{C}\right)$ for $1-4$ hours to reduce their activity. The wings and the legs of the cooled insects were amputated. The body was mounted ventral side up in the groove of a Plexiglas ${ }^{\circledR}$ holder and positioned so that the antennae were attached to a sticky wax layer, using strips of transparent tape $\left(\operatorname{Scotch}^{\circledR} 3 \mathrm{M} 810,19 \mathrm{~mm} \times 33 \mathrm{~m}\right.$ ). The head and scape of the antenna were fixed to the support with histology paraffin $\left(\mathrm{mp} 45^{\circ} \mathrm{C}\right)$ melted locally with a temperature controlled soldering iron $\left(50^{\circ} \mathrm{C}\right)$. The recordings preparation was 
Oviposition choice of $P$. xylostella on $B$. napus

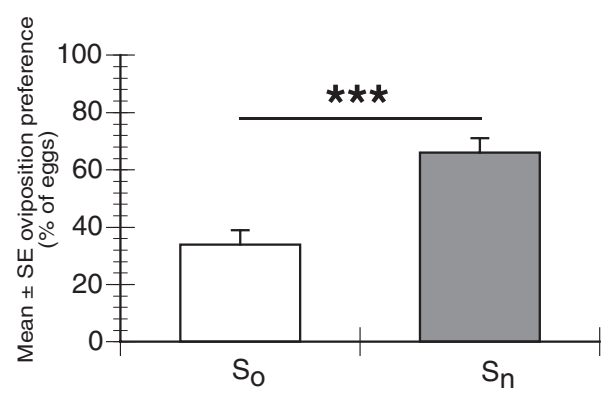

Oviposition choice of $P$. xylostella on artificial leaves

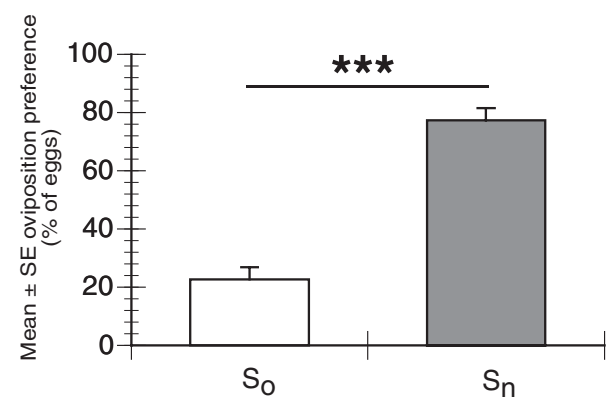

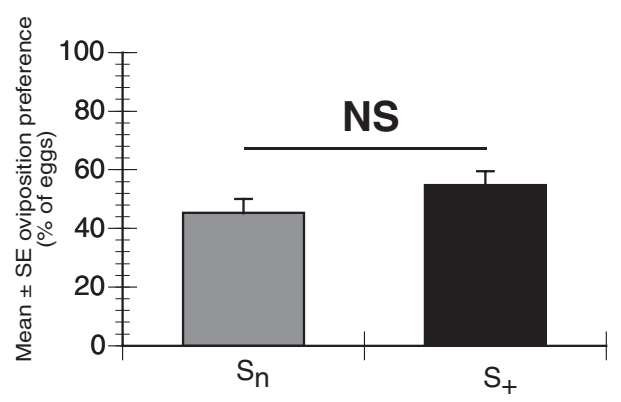

A Fig. 1 Effect of sulphur fertilisation on $P$. xylostella oviposition choice. (A) Oviposition choice assay with $B$. napus plants. Number of replicates: $n=9$ for $S_{0} / S_{n}$ and $\mathrm{n}=13$ for $\mathrm{S}_{\mathrm{n}} / \mathrm{S}_{+}$. These data are the same as in Marazzi \& Städler (2003) and shown here for comparison. (B) Oviposition choice assay with leaves treated with $B$. napus plant surface extracts (1 gle). Number of replicates: $\mathrm{n}=9$ for $\mathrm{S}_{0} / \mathrm{S}_{\mathrm{n}}$ and $\mathrm{n}=13$ for $\mathrm{S}_{\mathrm{n}} / \mathrm{S}_{+} \cdot \mathrm{S}_{0}=$ sulphur-free; $S_{n}=$ normal field-concentration of sulphur; B $\quad \mathrm{S}_{+}=$sulphur-rich mounted under a stereomicroscope and continuously humidified with a water-saturated air stream $\left(1 \mathrm{~m} / \mathrm{s}, 22 \pm 3^{\circ} \mathrm{C}\right)$. We used basically the same method as described by Guerin and Visser (1980). Briefly, the airflow was split into continuous and stimulatory airstreams at a $9: 1$ ratio, which converged prior to the electrophysiological preparation. The stimulatory air stream passed through a Pasteur pipette $(20 \mu \mathrm{m} \varnothing)$ containing the test compound $(100 \mu \mathrm{l})$ spread on a folded filter paper $(1.6 \times 5 \mathrm{~cm}$, paper from Schleicher \& Schuell) and upon activation of a valve, was injected into the continuous air stream. The indifferent electrode, filled with a saline solution (Kaissling 1995), was inserted in the base of the antenna and the recording electrode, containing saline plus $0.01 \%$ $(\mathrm{v} / \mathrm{v})$ of polyvinylpyrolidone solution, was brought in contact with the antennal tip. The EAG signal was recorded using a lab-built amplifier with high input impedance $\left(10^{13} \Omega\right)$ and low bias current $(<10 \mathrm{pA})$. The signals were filtered (electronic high-pass with cornering frequency of $0.001 \mathrm{~Hz})$, amplified $(100 \times)$ and digitised using SuperScope II 3.0 software (GW Instruments, Somerville, Massachusetts) on a Macintosh computer. The EAG amplitudes were determined using PowerChrom v2.2.4 (AD Instruments, Springs, Colorado) software. The $\mathrm{S}_{0}, \mathrm{~S}_{\mathrm{n}}$ and $\mathrm{S}_{+}$plant extracts were tested at a concentration of $0.04,0.1$ and 0.4 gle. Trans- 2 hexanal ( 1 and $10 \mu \mathrm{g}$ ) was used as control for antennal activity at the beginning and end of a test sequence. The set of stimuli was exposed sequentially to the insect in the following order: from $S_{0}, S_{n}$ to $S_{+}$, always starting with the lowest plant extract concentration. Responses to extracts were expressed as the mean of 5 pulses of $0.5 \mathrm{~s}$ with an interval of $5 \mathrm{~s}$. EAG measurements were replicated on 5 female antennae.

The EAG responses to plant extracts between the 3 groups of differently fertilised plants were analysed by ANOVA with the amplitude $(\mathrm{mV})$ of the EAGs as the dependent factor, type of treatment $\left(\mathrm{S}_{0}, \mathrm{~S}_{\mathrm{f}}\right.$ and $\left.\mathrm{S}_{+}\right)$and concentration $(0.04,0.1$ and 0.4 gle $)$ as independent factors $(\mathrm{n}=5)$. We performed multiple comparisons using a Bonferroni post-hoc test within each group of plant extracts to detect differences between concentrations.

\section{Results}

Oviposition choice on artificial leaves treated with surface extracts

The B. napus plants differing in $\mathrm{S}$ fertilisation tested by Marazzi and Städler (in preparation) (Fig. 1A) were extracted and yielded the material for these experiments. As shown in Fig. 1A, the oviposition choice of P. xylostella on real plants was affected by $\mathrm{S}$ concentration (Mann-Whitney U-test, $\mathrm{S}_{0}$ vs $\mathrm{S}_{\mathrm{n}}: \mathrm{n}=9, \mathrm{p}=0.0013$ and $\mathrm{S}_{\mathrm{n}}$ vs $\mathrm{S}_{+}$: $\mathrm{n}=13, \mathrm{p}=0.0956$ ). The wax-free methanolic leaf-surface extracts of plants fertilised with $\mathrm{S}$ proved to be active in the oviposition bioassays of $P$. xylostella (Fig. 1B). The number of eggs laid was significantly higher (Mann-Whitney U-test, $n=9, p=0.0003$ ) on artificial leaves sprayed with $S_{n}$ plant extracts than on artificial leaves sprayed with $S_{0}$ plant extract, representing an increase of nearly $250 \%$ on $\mathrm{S}_{\mathrm{n}}$ plant extracts. Similarly, a slight but not significant difference was found between the number of eggs laid on artificial leaves sprayed with $\mathrm{S}_{\mathrm{n}}$ and $\mathrm{S}_{+}$plant extracts (Mann-Whitney U-test, $\mathrm{n}=13, \mathrm{p}=0.0833$ ). Compared to $\mathrm{S}_{\mathrm{n}}, \mathrm{S}_{+}$-sprayed artificial leaves showed a $24 \%$ increase in oviposition.

\section{Chemical analysis of $B$. napus plant extracts}

Eight GSLs were consistently detected in all tissue from the three populations of B. napus tested (Fig. 2A). These included the alkene GSL, 3-butenyl (gluconapin), two hydroxy-alkenes GSLs, 2-hydroxy-3-butenyl (progoitrin) 
A
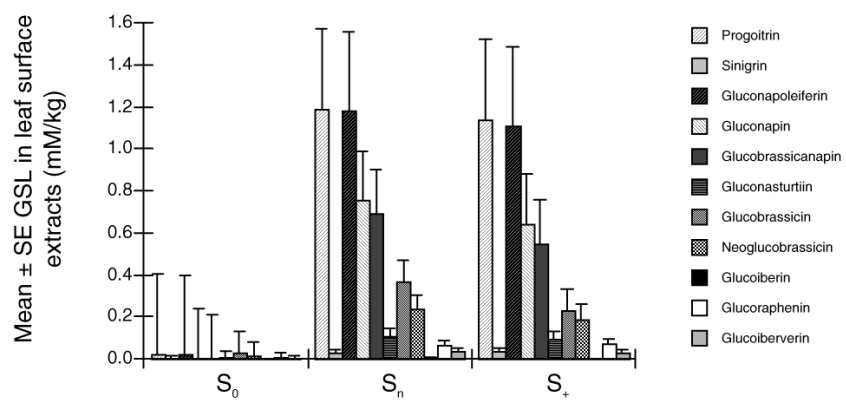

B
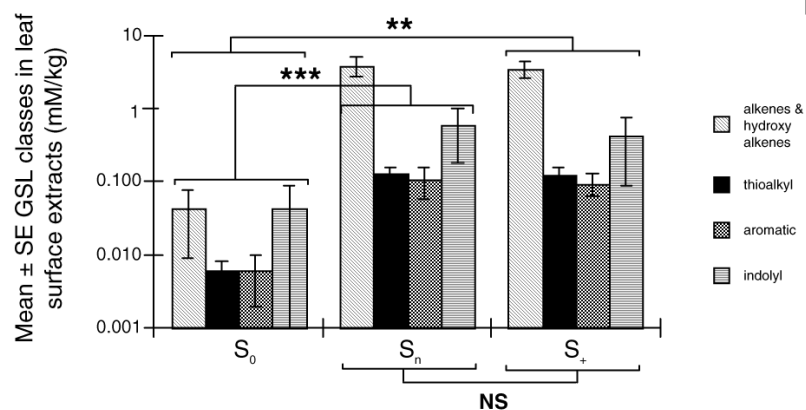

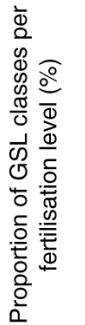

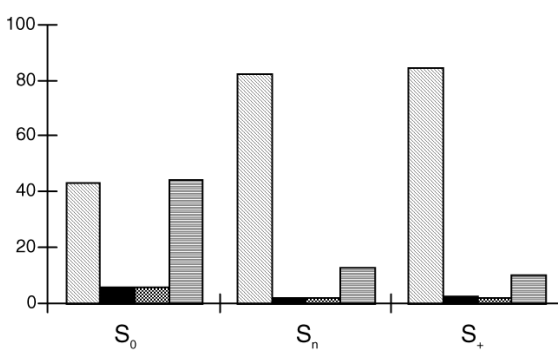

Fig. 2 Analytical data of the glucosinolates content of B. napus plants. (A) Profiles of individual glucosinolates for $S_{0}, S_{n}$ and $S_{+}$ B. napus plants. Number of replicates: 5. Abbreviations: as in Fig. 1. (B) Profiles of glucosinolate in a logarithmic scale. Number of replicates: 5. (C) Proportion of the glucosinolate classes. Interaction (ANOVA) between sulphur fertilisation vs group of GSL: $\mathrm{p}<0.001$

and 2-hydroxy-4-pentenyl (gluconapoleiferin), two thioalkyl GSLs, 4-methylsulphinyl-3-butenyl (glucoraphenin) and 3-methylthiopropyl (glucoiberverin); two indolyl GSLs, 3-indolylmethyl (glucobrassicin) and 1-methoxy- 3-indolylmethyl (neoglucobrassicin) and the aromatic GSL 2 phenylethyl (gluconasturtiin). Moreover, we found three additional GSLs in $\mathrm{S}_{\mathrm{n}}$ and $\mathrm{S}_{+}$plant extracts: two alkene GSLs, 2-propenyl (sinigrin) and 4-pentenyl (glucobrassicanapin), and a thioalkyl GLS, 3-methylsulphinylpropyl (glucoiberin) (Fig. 2A). The concentrations given in $\mathrm{mM} / \mathrm{kg}$ of leaf extract of the individual GSLs detected in $\mathrm{S}_{\mathrm{n}}$ and $\mathrm{S}_{+}$plant extracts were overall higher than those found in $S_{0}$ plant extracts (Fig. 2B). The proportions of individual GSLs classes varied considerably also between the plant extracts (Fig. 2C). The proportion of progoitrin observed in $\mathrm{S}_{\mathrm{n}}$ and $\mathrm{S}_{+}$ plant extracts $\left(\mathrm{S}_{\mathrm{n}}=1.188, \mathrm{~S}_{+}=1.141 \mathrm{mM} / \mathrm{Kg}\right.$ leaf surface $)$ was around 60 times larger than that found in $S_{0}$ plant extracts $(0.019 \mathrm{mM} / \mathrm{Kg}$ leaf surface). Similarly, the proportion of gluconapoleiferin was about 50 times larger in $S_{n}$ and

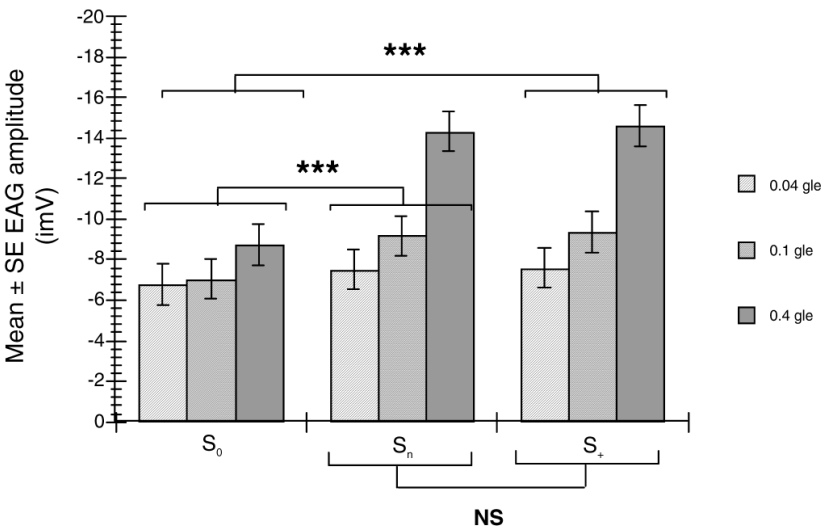

Fig. 3 Electroantennogram responses to B. napus surface extracts of plants differing in $S$ nutrition. The plant extracts were tested in three different concentrations: $0.04,0.1$ and 0.4 gle (gram leaf equivalent). Values are given as means \pm of 5 stimulations per antenna (insect) and per concentration. Number of replicates: 5 insects. The dose-dependent relationship between concentration and female antennal response was tested by a Bonferroni-test, $\mathrm{n}=5$, 0.04-0.1 gle: $\mathrm{p}=0.0029,0.04-0.4$ gle, $\mathrm{p}<0.0001,0.1-0.4$ gle: $\mathrm{p}<0.0001$. Abbreviations: as in Fig. 1

$\mathrm{S}_{+}$than in $\mathrm{S}_{0}$ plant extracts. The greatest proportional difference was found with gluconapin, whose concentration was between 650 and 750 times higher in $S_{n}$ and $S_{+}$versus $S_{0}$ plant extracts. Quantitatively, the total GSLs detected showed differences that were between 10 and 30 times higher in $\mathrm{S}_{\mathrm{n}}$ and $\mathrm{S}_{+}$versus $\mathrm{S}_{0}$ plant extracts (Fig. 2A). The potential presence of volatile breakdown products of GSLs, the isothiocyanates, was assed by GC-MS analysis. Isothiocyanates were not present in any of the tested plant extracts (detection threshold: $1.5 \mu \mathrm{g} / \mathrm{ml}$ crude extract).

\section{Electroantennogram response to B. napus plant extracts}

The EAG responses of female moths of $P$. xylostella to leaf surface extracts of $S_{0}, S_{n}$ and $S_{+}$tested at three increasing concentrations are shown in Fig. 3. Mean EAG responses elicited by the test compounds ranged from about 0.1 (at 0.04 gle, mainly $\mathrm{S}_{0}$ plant extracts) to $3 \mathrm{mV}$ (at 0.4 gle, mainly $S_{n}$ and $S_{+}$plant extracts). All concentrations of $S_{0}$ extracts tested induced significantly lower responses than those of $\mathrm{S}_{\mathrm{n}}$ or $\mathrm{S}_{+}$extracts (Bonferroni, $\mathrm{n}=5, \mathrm{p}<0.001$,). Conversely, no significant difference was found between the EAG recordings for $\mathrm{S}_{\mathrm{n}}$ - and $\mathrm{S}_{+}$-plant extracts (Bonferroni, $\mathrm{n}=5, \mathrm{p}=0.5490$, Fig. 3A). EAG amplitudes were clearly concentration dependent and peaked at the highest dose tested $(0.4 \mathrm{gle})$ for all three plant extracts tested.

\section{Correlations between behaviour and chemical analysis}

The lack of $\mathrm{S}$ nutrition dramatically affected the GSL content of the plants, corresponding well to the results of the behavioural assay described in Fig. 1. The significant differences in the female antennal perceptions revealed by EAG recordings were exactly mirrored by the GSL content of plant extracts. 


\section{Discussion}

Oviposition preference influenced by leaf surface extracts

The acceptability of B. napus for P. xylostella was markedly affected by the $S$ nutrient levels of the plant. The lack of $S$ in the plant nutrient solution reduced oviposition on both real plants and artificial leaves. Surprisingly, the differences detected with sprayed surrogate leaves were more pronounced. Our study seems to be the first showing the direct role of fertilisation on plant secondary metabolites in influencing oviposition behaviour. Our results are in contrast with previous publications comparing Brassica species differing in GSL levels (Pivnick et al. 1994; Bodnaryk 1997). These authors concluded that species like P. xylostella are insensitive to sinigrin and suggested that its pest status on low-GSL lines would be likely to remain unchanged. Possible reasons for this disparity might be the followings: 1) "low GSL varieties" are not comparable to the effect of plant S-deficiency, 2) these plants are known to have a lower content of GSLs only in the seeds, but not necessarily in other plant parts (Fahey et al. 2001) and 3) in our experiments, extreme variations in the levels of S-supply were used, making the differences between the three entries more evident. It is therefore conceivable that in the behavioural choices made by the insect, only the threshold between undetectable/detectable presence of GSLs was qualitatively important and not the quantitative difference. However, other plant metabolites are certainly also influenced by the $\mathrm{S}$ shortage and may therefore have affected the oviposition behaviour positively or negatively. Further, some of these metabolites are not volatile and thus cannot be detected by the olfactory sensilla. In addition, the final response of an insect in accepting or rejecting a particular plant is mediated by a balance of positively and negatively interpreted sensory signals evoked by plant chemicals. In this respect, it should be noted that negative (inhibitory) effects of the plant extracts were not more specifically tested.

\section{Non-volatiles in leaf surface extracts}

In the present study, we found that the higher the S application, the higher the total GSL content. Mainly the abundance of the alkenes and the thioalkyl increased whereas the aromatic and indolyl classes were comparatively unaffected. It is interesting that $\mathrm{S}$ affected not only the quantities of GSLs but also the qualitative proportions (Fig. 2C). The different patterns in the four groups of GSLs in response to $\mathrm{S}$ can be explained by their amino acid precursors (Schnug \& Hanecklaus 1994). Indolyl and aromatic GSLs are derived from tryptophan and tyrosine respectively, and their biosynthesis requires two S-containing compounds: cysteine and adenosyl-5'-phosphosulphate (APS) (Mithen 2001). In contrast the synthesis of alkenes and thioalkyl GSLs depends on three S sources: methionine, cysteine and APS. Given this difference in $\mathrm{S}$ requirement at the biosynthetic level, thioalkyl and alkene (synthesised via modification of the side chain of thioalkyl) GSLs might be more sensitive to the plant $S$ status. The effect of $S$ application on the total GSL content is in agreement with the observations of Schnug \& Hanecklaus (1994) showing that the S nutritional status of the plants exerts a considerable effect on the GSL content. Similarly Mailer (1989) and Scherer (2001) reported that $\mathrm{S}$ application up to $100 \mu \mathrm{g} \mathrm{mL}^{-1}$ raised the GSL concentration in the rapeseed cv. Wesbrook (B. napus L.). Interestingly, Mailer (1989) found that a nutrient solution provided with an excess of $\mathrm{S}\left(200 \mu \mathrm{g} \mathrm{mL}^{-1}\right)$, lowered the GSL concentration. This could explain why, in our results, $\mathrm{S}_{+}$values were not always higher than $\mathrm{S}_{\mathrm{n}}$.

After landing on a host plant, contact stimuli can influence oviposition. In the case of $P$. xylostella, individual GSLs, including sinigrin and glucobrassicin, certainly play an important role in host recognition and oviposition stimulation (Reed et al. 1989; Renwick 2002), as well as in larval feeding, as reported by Van Loon et al. (2002). This function is synergised by surface waxes, as demonstrated by Spencer et al. (1999), who reported only limited oviposition stimulant activity of sinigrin or cabbage homogenates in the absence of wax.

\section{Volatiles in leaf surface extracts}

In agreement with the behavioural and analytical data, antennal olfactory responses (EAGs) to the extracts were also significantly stronger for $S_{n}$ and $S_{+}$plants than for $S_{0}$ plants. Extracts of host-plant volatiles are most likely involved in host location as shown by Palaniswamy et al. (1986) and also enhance egg deposition rate in P. xylostella. Reed et al. (1989) identified intact glucosinolates in hostplant extracts stimulating oviposition and found that degradation with myrosinase or sulphatase largely eliminated the activity, thus excluding isothiocyanates, as active principles. Pivnick et al. (1994) studied attraction of the moths and found that allyl-isothiocyanates was an attractive component in homogenised plant volatiles but it was virtually absent from intact plant volatiles. The authors performed a gas chromatographic fractionation of these volatiles and found a terpene-containing fraction to be most attractive, whereas no isothiocyanates were present. Justus et al. (unpubl.) recorded GC-EAGs of headspace extracts from two host and non-host plants of $P$. xylostella and identified several EAG active components, but again no evidence was found that isothiocyanates matched the most stimulating compounds. All these results seem to be in agreement with our findings that isothiocyanates do not, or only in minute quantities, occur in the behaviourally active extracts. On the other hand, Renwick et al. (in preparation) have found convincing evidence that some isothiocyanates stimulate oviposition. These same compounds also produced matching EAG activities, so that apparently isothiocyanates do have some role to play in host-plant selection of $P$. xylostella. Renwick and Radke (1990) provided clear evidence that several chemically different compounds are involved in the stimulation of the diamondback moth oviposition. Therefore, it can be assumed that the extracts tested in our study contain also a mixture of compounds that might, individually or in combination, stimulate oviposition. The highly active plant extracts obtained in this study would be a good basis to investigate the relative importance of volatile and nonvolatile compounds, because as we showed, they match the response to intact plants very well indeed. 
The most important result of practical interest of this work is the fact that no significant differences between $S_{n}$ and $\mathrm{S}_{+}$plants were noted. Consequently, as sulphur fertilisation approaches the optimal level for rape, the crop plant will have no further influence on attack or population increase rates of its pest. Within the range tested in this investigation, $\mathrm{S}$ fertilisers that allow optimal harvests do not lead to increased infestation by $P$. xylostella.

\section{Acknowledgments}

Thanks are due to Ms. Astrid Bächli and Dr Ignaz Bürge for valuable help with the chemical analyses and Mrs. Jean Berüter-Cassels for editorial assistance. We thank Dr A. Barker as well as the two referees for valuable comments on the manuscript. This research was included in the COST ACTION NR 829 and supported by the Federal Office for Education and Sciences (project number C 98.0096). The research of E. Städler was supported by a grant of the Swiss National Science Foundation 31-65016.01.

\section{References}

Baur R, Birch ANE, Hopkins RJ, Griffiths DW, Simmonds MSJ, Städler E (1996) Oviposition and chemosensory stimulation of the root flies Delia radicum and D. floralis in response to plant and leaf surface extracts from resistant and susceptible Brassica genotypes. Entomol Exp Appl 78: 61-75

Blight M, Pickett J, Wadhams L, Woodcock C (1995) Antennal perception of oilseed rape, Brassica napus (Brassicaceae), volatiles by the cabbage seed weevil Ceutorhynchus assimilis (Coleoptera, Curculionidae). J Chem Ecol 21: 1649-1663

Bodnaryk RP (1997) Will low-glucosinolate cultivars of the mustards Brassica juncea and Sinapsis alba be vulnerable to insect pests? Can J Plant Sci 77: 283-287

Chew FS (1988) Biological effects of glucosinolates. Pp 155-181 in Cutler HG (ed) Biologically active natural products: potential use in agriculture. USA, WA-Washington, D.C.: American Chemical Society

Fahey JW, Zalcmann AT, Talalay P (2001) The chemical diversity and distribution of glucosinolates and isothiocyanates among plants. Phytochemistry 56: 5-51

Griffiths DW, Deighton N, Birch ANE, Patrian B, Baur R, Städler E (2001) Identification of glucosinolates on the leaf surface of plants from the Cruciferae and other closely related species. Phytochemistry 57: 693-700

Guerin P, Visser J (1980) Electroantennogram responses of the carrot fly, Psila rosae, to volatile plant components. Physiol Entomol 5: 111-119

Gupta PD, Thorsteinson AJ (1960a) Food plant relationships of the diamond-back moth (Plutella maculipennis (Curt.)). II. Sensory regulation of oviposition of the adult female. Entomol Exp Appl 3: 241-250

Gupta PD, Thorsteinson AJ (1960b) Food plant relationship of the diamond-back moth (Plutella maculipennis (Curt.)). I. Gustation and olfaction in relation to botanical specificity of the larva. Entomol Exp Appl 3: 241-250

Received 12 September 2003; accepted 18 November 2003.
Harcourt DG (1957) Biology of the diamondback moth, Plutella maculipennis (Curt.) (Lepidoptera: Plutellidae), in eastern Ontario. II. Life-history, behaviour, and host relationships. Can Entomol 89: 554-564

Hughes PR, A RJ, Lopez KD (1997) New oviposition stimulants for the diamondback moth in cabbage. Entomol Exp Appl 85: 281-283

Hurter J, Ramp T, Patrian B, Städler E, Roessingh P, Baur R, De Jong R, Nielsen JK, Winkler T, Richter WJ, Müller D, Ernst B (1999) Oviposition stimulants for the cabbage root fly: isolation from cabbage leaves. Phytochemistry 51: 377-382

Justus KA, Mitchell BK (1996) Oviposition site selection by diamondback moth, Plutella xylostella (L.) (Lepidoptera: Plutellidae). J Insect Behav 9: 887-898

Kaissling K-E (1995) Single unit and electroantennogram recordings in insect olfactory organs. Pp 361-377 in Spielman AI, Brand JG (eds) Experimental Cell Biology of Taste and Olfaction. USA, FL-Boca Raton: CRC Press

Mailer RJ (1989) Effects of applied sulphur on glucosinolate and oil concentrations in the seeds of rape (Brassica napus L.) and turnip rape (Brassica rapa L. var. silvestris (Lam.) Briggs). Aust J Agric Res 40: 617-624

Meyer GA (2000) Interactive effects of oil fertility and herbivory on Brassica nigra. Oikos 88: 433-441

Mithen R (2001) Glucosinolates - biochemistry, genetics and biological activity. Plant Growth Regul 34: 91-103

Palaniswamy PC, Gillot C, Slater GP (1986) Attraction of diamondback moth, Plutella xylostella (L.) (Lepidoptera: Plutellidae), by a volatile compounds of canola, white mustard, and faba bean. Can Entomol 118: 1279-1285

Pedras M, Okanga F, Zaharia I, Khan A (2000) Phytoalexins from crucifers: synthesis, biosynthesis, and biotransformation. Phytochemistry 53: 161-176

Pivnick KA, Jarvis BJ, Slater GP (1994) Identification of olfactory cues used in host-plant finding by diamondback moth, Plutella xylostella (Lepidoptera: Plutellidae). J Chem Ecol 20: 1407-1427

Reed DW, Pivnick KA, Underhill EW (1989) Identification of chemical oviposition stimulants for the diamondback moth, Plutella xylostella, present in three species of Brassicaceae. Entomol Exp Appl 53: 227-286

Renwick JAA, Radke CD (1990) Plant constituents mediating oviposition by the diamondback moth, Plutella xylostella (Lepidoptera: Plutellidae). Phitophaga 3: 37-46

Renwick JAA (2002) The chemical world of crucivores: lures, treats and traps. Entomol Exp Appl 104: 35-42

Roessingh P, Städler E (1990) Foliar form, colour and surface characteristics influence oviposition behaviour of the cabbage root fly Delia radicum. Entomol Exp Appl 57: 93-100

Scherer HW (2001) Sulphur in crop production - invited paper. Eur J Agron 14: 81-11

Schnug E, Haneklaus S (1994) Sulphur deficiency in Brassica napus - Biochemistry - Symptomatology - Morphogenesis. Landbauforschung Voelkenrode Sonderheft 144

Schnug E (1997) Significance of sulphur for the quality of domesticated plants. Pp 109-130 in Cram WJ (ed) Sulphur metabolism in higher plants Vol 3. NL-Leiden: Backhuys

Spencer JL, Pillai S, Bernays E (1999) Synergism in the oviposition behaviour of Plutella xylostella: sinigrin and wax compounds. J Insect Behav 12: 483-500

Van Loon JJA, Wang CZ, Nielsen JK, Gols R, Qiu YT (2002) Flavonoids from cabbage are feeding stimulants for diamondback moth larvae additional to glucosinolates: Chemoreception and behaviour. Entomol Exp Appl 104: 27-34 